\title{
Power quality as a reliability problem for electronic equipment
}

\author{
A. Victor A. Anunciada ${ }^{1,3}$, Hugo Ribeiro ${ }^{2,3}$ \\ ${ }^{1}$ Department of Electrical and Computer Engineering, Instituto Superior Técnico, Universidade Técnica de Lisboa \\ Avenida Rovisco Pais, 1, 1049-001 Lisboa, Portugal \\ phone:+351 218418 385, fax: +351 218418 385, e-mail: avaa@lx.it.pt, \\ ${ }^{2}$ Escola Superior de Tecnologia, Instituto Politécnico de Tomar, \\ Estrada da Serra, 2300 Tomar \\ phone:+351 249328 150, e-mail: hugo@ipt.pt \\ ${ }^{3}$ Instituto de Telecomunicações \\ Torre Norte, piso 10 \\ Avenida Rovisco Pais, 1, 1049-001 Lisboa, Portugal
}

\begin{abstract}
Power quality standards introduce the definitions of several power quality disturbances and define limits for their amplitudes, repetition rates and, or maximum number of occurrences in a time period. The definitions of those parameters result from the observation of the disturbance phenomena in the networks and are not related with the consequences of power quality disturbances in the reliability of electronic equipments. In this paper, are described the main reliability effects caused by power quality problems, in electronic equipment. The authors explain the physical limitations of power supplies, concerning power quality problems and developed a simple, low cost power quality analyser, designed for the evaluation of the parameters that are critical to the failure rates of electronic equipment.
\end{abstract}

Key words: Power Quality, Power Supplies, Reliability of Electronic Equipment.

\section{Introduction}

An important concern related with power quality is the economic value of failure and breakdown of electronic equipment connected to the mains supply. It is an increasing concern, considering that microprocessors, other electronic control devices and power electronics are increasingly involved in all electrical equipments and, consequently, in almost all human activities, in the developed countries.

Power quality evaluation is based on the measurement of several types of disturbances, affecting voltage and frequency in the mains supply. The definitions of power disturbances include the most common phenomena observed in the mains networks, especially related with the voltage waveform. And the existing standards do not consider the effects of those disturbances on the electronic equipments.

\section{Power Supplies}

The interface between the mains network and any electronic equipment is a switch mode power supply (SMPS). Every electrical device including electronic control, require a power supply for the polarization of the electronic devices. Even in power electronics systems, the control circuitry is fed by an auxiliary SMPS. Consequently, the failure analysis of electronic circuits, due to power quality problems, implies the knowledge of the SMPS behaviour, under abnormal situations of the $\mathrm{AC}$ input.

The Fig. 1 shows the basic building blocks of a SMPS. The input filter (Fig. 2) is intended to suppress radio frequency noise that results from transistor switching transitions in the DC-AC square wave converter. Typically, it presents an attenuation of 30 to $50 \mathrm{~dB}$, at frequencies above 1 to $5 \mathrm{MHz}$ and is designed to operate with noise amplitudes up to 1 to $5 \mathrm{mV}$. This filter is not efficient in the limitation of high amplitude, or high energy transients. The capacitances $C_{X}$ and $C_{Y}$ are very small $(<100 \mathrm{pF})$ and are designed to present a low impedance at frequencies higher than $1 \mathrm{MHz}$. The input protection of SMPS includes usually an overvoltage protection, as shown in Fig. 2. In this case, a group of 3 transient suppressors in series is mounted at the output of the filters. Those suppressors are in parallel with the line input and can afford an energy dissipation of less than 10J. An high energy transient blows the suppressors and, afterwards, damage the converters. The time response of those devices is quite low $(<10 \mathrm{~ns})$, but it is not sufficiently low to provide an accurate protection of sensitive devices, like power MOSFETS. In conclusion, the input filter of a SMPS is designed with a single objective - compliance with electromagnetic

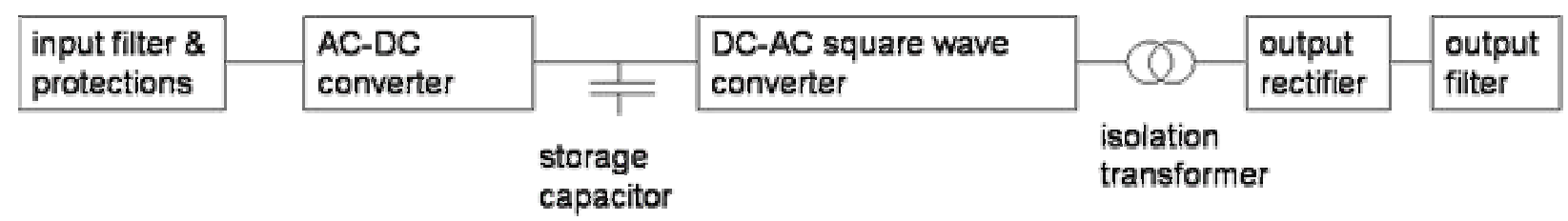

Fig. 1. Building blocks of a switch mode power supply 
compatibility standards - and does not provide any protection of the power supply against the line input disturbances.

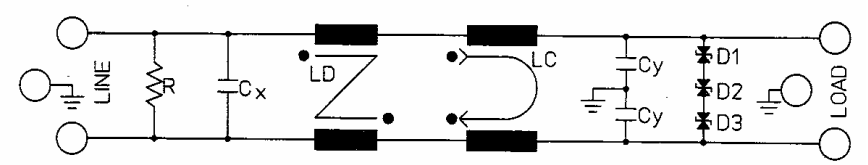

Fig. 2. Radio frequency input filter of switch mode power supplies

Some SMPS manufacturers introduce, at the system input, an overvoltage protection that blows the input fuse, when the input voltage remain higher than $110 \%$ up to $130 \%$ of the nominal value. Those protections include a voltage detection circuit and a thyristor, and are very

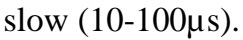

The AC/DC conversion is usually obtained with a diode bridge and capacitive filtering. The output voltage is approximately equal to the peak voltage of the mains input. The capacitor is a bulky storage device, due to two different design objectives:

- reduction of the residual AC component of the voltage (few volts peak to peak);

- energy storage that permits the operation of the power supply, during a short interruption of the mains supply, even when it works at full power; the allowed interruption time is typically $30 \mathrm{~ms}$ up to $60 \mathrm{~ms}$ (standon time), without any variation of the output voltage.

The storage capacitor is charged at the peak value of the input voltage and the DC-AC converter is designed to operate at that voltage, with some tolerance interval. A lower input voltage implies higher currents in the DC-AC converter and, consequently, higher operating temperatures. A correct rms value of the input voltage is not sufficient to avoid the SMPS overheating. Very often, the rms value is acceptable and the peak value of the voltage is much lower than $\mathrm{v} 2 . \mathrm{V}_{\mathrm{rms}}$, due to the effect of voltage distortion $\left(3^{\text {rd }}, 5^{\text {th }}\right.$ and $7^{\text {th }}$ harmonics $)$.

The storage capacitors are large electrolytic capacitors, performing a good filtering effect at $100 \mathrm{~Hz}$. Their equivalent series resistance (ESR) and equivalent series inductance (ESL) are very large. Consequently their impedance rises for frequencies above some few $\mathrm{kHz}(1-$ $10 \mathrm{kHz}$ ), resulting in a very poor filtering effect at higher frequencies. Additional capacitors, with a better frequency response, are usually connected in parallel, to avoid an excessive noise introduced by the DC-AC converters due to device switching. However their capacity is small.

When the storage capacitor is discharged, and input switch is turned on, the peak value of the input current is extremely high and must be limited. Most manufacturers use a NTC resistor in series with the SMPS input. During the first seconds of operation, resistor warms up and its resistance decreases. At normal operation, the voltage drop along this resistance is small enough to do not compromise the SMPS efficiency. The thermal time constant of those resistances is usually 5-10s.
Consequently, the occurrence of a power failure with a restart in less than 10s is dangerous to the integrity of the input rectifier, because the NTC resistor is hot and does not limit the inrush current and input fuse may be not sufficiently fast to avoid the effects of the overcurrent.

Some equipments, complying with EN 61000 standard, use a boost converter (Fig.3), in order to perform input current waveshaping. In this case, the DC voltage is $15 \%$ to $25 \%$ higher than the mains input voltage peak value $(360 \mathrm{~V}-400 \mathrm{~V}$, for $230 \mathrm{~V} \mathrm{AC}$ input). The use of this auxiliary converter introduces the regulation of the storage capacitor voltage, which remains almost independent of the mains voltage. Even in this case, the storage capacitor remains bulky, because the design objectives are not modified.
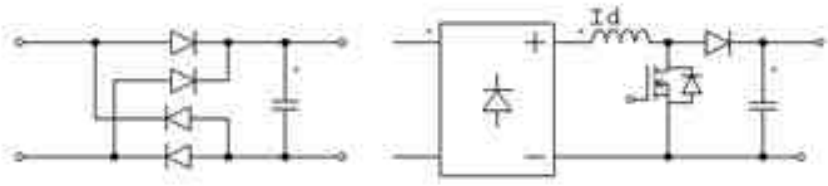

Fig. 3. AC-DC conversion in a SMPS, without and with input current waveshaping

The use of the boost converter permits the operation of the SMPS in the extended range of input voltage (80$240 \mathrm{~V}_{\text {rms }}$ ), without any commutation in the input rectifier. The control circuitry turns off the power supply when the input voltage exceeds the maximum value. Consequently, SMPS complying with standard EN 61000 and operating in the extended input voltage range are very insensitive to the input voltage disturbances, if those disturbances are slow and smooth.

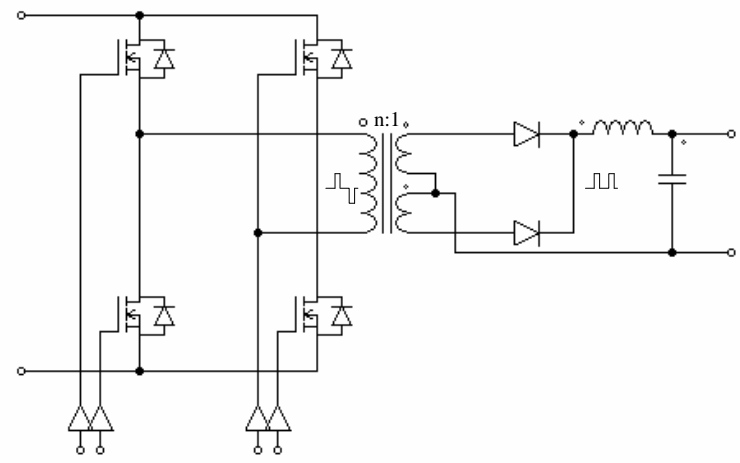

Fig. 4. Isolated full-bridge converter with output rectifier and LC filter - the power circuit topology used in medium and high power SMPS

Several topologies of DC-AC converters are used in SMPS. All of them present a high frequency transformer, required in order to obtain input to output isolation. The physical size of those transformers is an important factor on the SMPS manufacturing costs, justifying the increase of switching frequency of the converters up to the limits permitted by the electronic devices and materials. The size reduction and leakage induction minimization imply a considerable leakage capacitance between primary and secondary. Additional capacitances to ground are used in order to reduce common mode noise and avoid some stability problems, due to the leakage capacitances of the transformer. 
The control circuits of SMPS vary the width of the pulses in the transformer primary, in order to regulate the output voltage (pulse width modulation). Usually, the output voltage control uses a PI regulator, in order to obtain a high gain at low frequencies $(<1 \mathrm{kHz})$. The time response of the control is quite slow $(0.2-1 \mathrm{~ms})$. Consequently, if the input voltage presents high voltage positive notches, with a short duration, the storage capacitor charges and the corresponding voltage is transmitted to the DC-AC converter. Even in the case of SMPS with the boost converter at the input, the notch overvoltage affects the storage capacitor voltage, due to the excessive time response of the boost control (typ. > 10ms). Negative notches do not affect significantly the capacitor voltage and, consequently, do not disturb the SMPS operation.

An overvoltage at the storage capacitor is transmitted to the secondary of the isolation transformer and may have several effects, namely breakdown in the rectifier diodes and excessive output voltage.

As previously referred, a low input voltage does not affect the operation of SMPS with input current waveshaping. However, other power supplies are very sensitive to low input voltage, or harmonic distortion.

In the design of SMPS, the main concerns are cost and volume limitations, overall efficiency and electromagnetic compatibility requirements. The result is a product working properly with a sinusoidal input voltage, with an extended tolerance of its rms value, harmonic content and even short interruptions.

The main reliability problems, concerning power quality disturbances, are due to fast variations of the input voltage, namely:

- positive notches, with high voltage peaks $(>50 \mathrm{~V})$, as occurs at the interruption of inductive loads (resistance welding, for instance)

- moderate overvoltage may blow the input fuse, due to the action of the overvoltage protection

- SMPS without input current waveshaping (low power factor SMPS) are very sensitive to low voltage operation, harmonic distortion in the input voltage, if it reduces the peak value of the voltage, and short interruptions with hot restart

- fast transients, even with low amplitudes $(<10 \mathrm{~V})$, at the input voltage, may be not suppressed by the SMPS and appear at the DC output voltage; the critical parameters are $\mathrm{dv} / \mathrm{dt}(>100 \mathrm{~V} / \mu \mathrm{s})$ and amplitude.

It is very difficult to predict, measure and record transient phenomena with destructive effects in SMPS. Load switching and electrostatic discharge are the more frequent origin of transient phenomena. Another origin of high frequency noise is the neutral to ground voltage. In all the measurements, in office and factory buildings, where the line to neutral voltage was larger than $10 \mathrm{~V}$, we have detected fast transients and high frequency noise with amplitudes that may cause SMPS failures and interference in digital and analogic electronic boards. The common mode noise, present in line and neutral, is potentially dangerous to the electronic equipment, causing errors and even semiconductor breakdown.

Input voltages with very high distortion levels, THD $>30 \%$ or even more, do not introduce relevant reliability problems in the SMPS. In some input boost converters, with slower controllers, it is possible to arise some overheating, when THD is very high. However, we have not reported any fails in the units already tested.

\section{The CBEMA curves and modern SMPS}

Most authors refer IEEE Standard 446 and CBEMA curves (Computer Business Equipment Manufacturers Association) as a power quality target (fig. 5), for computers and electronic equipment. In fact, the major reliability problems are not related with the static rms value of the input voltage. And modern power supplies permit variations of the rms value larger then the limits defined by CBEMA curves. Considering the tolerance of the input rms voltage, nowadays the steady-state minimal tolerances are $15 \%$. A short interruption of $30 \mathrm{~ms}$ is always very well tolerated (min. stand-on time), without any regulation loss at the SMPS output. Overvoltages of $150 \%$, during $1 / 10$ of the period, should be acceptable. However, the behaviour of the SMPS in the presence of an overvoltage with that amplitude is not reliable, nor reproducible. If we apply a sinusoidal waveform starting at zero voltage, we would not have any failure. If the input voltage is at its peak value and then jumps 50\%, the probability of failure is very high (Fig. 6). SMPS with power factor correction are less sensitive to input overvoltage, depending on the time response of the boost control circuit. However they remain sensitive to high $\mathrm{dv} / \mathrm{dt}$ perturbations, due to the parasitic capacitance of the input inductor.

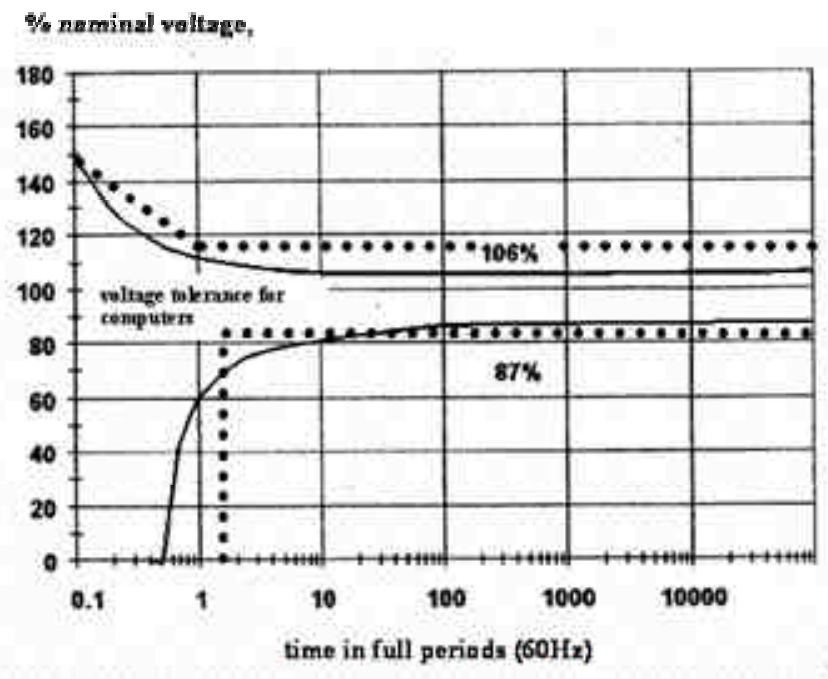

Fig. 5. CBEMA curves for voltage tolerance of computers; points indicate the evolution of those tolerances for modern power supplies 


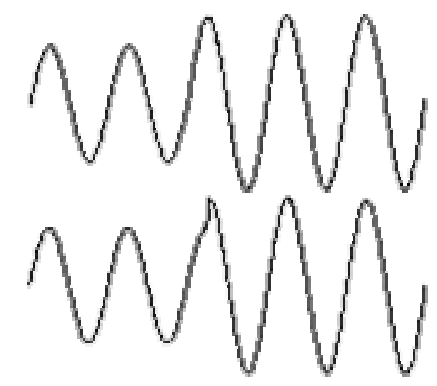

Fig. 6. Overvoltage at the input of a SMPS: with or without a fast voltage transient - an important difference concerning reliability

\section{Power Quality Parameters}

The experience of the authors, in the analysis of electronic equipment failures due to power quality problems, shows that expensive PQ monitoring equipments are not very useful. In fact, those equipments measure almost all the parameters defined by $P Q$ standards, which present a moderate influence on the electronic equipment reliability. However, the detection of notches, high frequency surges and transients is not accurately done.

The continuous detection and measurement of the disturbances listed in Table I reveal the reliability problems of the most frequently used electronic equipment.

The voltages and time derivatives referred in Table I apply to $230 \mathrm{~V}$ input, or to SMPS with extended input range. For other voltages, lower than $230 \mathrm{~V}$, the reduction of the voltages proportionally is an acceptable approach, but not very reliable, because those values depend on the breakdown voltages of power semiconductors and other specifications of capacitors and other electronic components.

\section{Power Quality Monitoring for Reliability Evaluation}

The main design objective of the PQ monitor developed by the authors was to achieve a low cost analyser for permanent monitoring of the mains network, in office and factory environment. The objective of this monitoring is to evaluate the necessity of corrective measures in the network, such as the installation of UPSs and diesel generators, or improvements of ground connections, cabling and so on. Those corrective measures are usually expensive and the corresponding decisions must be based on the evaluation of disturbances and statistics of their occurrence.

A few number of parameters have been selected, based on their importance, accordingly to Table I. For the selected parameters, it is necessary to evaluate the frequency of occurrence, counting the number of perturbations or the total time of occurrence.

The parameters considered are:
TABLE I

\begin{tabular}{|c|c|c|}
\hline Phenomena & $\begin{array}{l}\text { Magnitude, Time } \\
\text { and Frequency }\end{array}$ & Main Effects \\
\hline $\begin{array}{l}\text { Transients } \\
\text { oscillatory }\end{array}$ & $\begin{array}{l}>50 \mathrm{kHz} \\
>1.5 \mathrm{~V} \text {, depending } \\
\text { on frequency }\end{array}$ & $\begin{array}{l}\text { no effect on SMPS } \\
\text { may be transmitted } \\
\text { to the output, errors } \\
\text { on logic devices, } \\
\text { disks... }\end{array}$ \\
\hline Transients impulsive & $\begin{array}{l}\mathrm{dv} / \mathrm{dt}>100 \mathrm{~V} / \mu \mathrm{s}, \text { any } \\
\text { amplitude }\end{array}$ & $\begin{array}{l}\text { dv/dt and amplitude } \\
\text { are critical; SMPS } \\
\text { remain operating; } \\
\text { supplied equipment } \\
\text { may have important } \\
\text { failures }\end{array}$ \\
\hline $\begin{array}{l}\text { Positive, high } \\
\text { amplitude notches }\end{array}$ & $>50 \mathrm{~V},>1 \mathrm{~ms}$ & $\begin{array}{l}\text { amplitude and } \\
\text { response time of the } \\
\text { SMPS control are } \\
\text { critical; destructive } \\
\text { in SMPS without } \\
\text { boost converter }\end{array}$ \\
\hline $\begin{array}{l}\text { Voltage reductions, } \\
\text { interruptions, sags, } \\
\text { swell (1) }\end{array}$ & $\begin{array}{l}\text { up to stand-on time } \\
\text { above stand-on time }\end{array}$ & $\begin{array}{l}\text { no effects } \\
\text { power failure, errors } \\
\text { on logic devices } \\
\text { equipment shutdown }\end{array}$ \\
\hline Overvoltage (2) & $\begin{array}{l}>115 \% \text { of nom. input } \\
\text { voltage }\end{array}$ & $\begin{array}{l}\text { power fail, errors on } \\
\text { logic devices } \\
\text { equipment shutdown }\end{array}$ \\
\hline (1) \& (2), repetitive & $\begin{array}{l}>\text { stand-on time; } \\
>115 \% \text { nom. input } \\
\text { voltage; > } 2 \text { per min. }\end{array}$ & $\begin{array}{l}\text { repetitive shutdown } \\
\text { input rectifier and } \\
\text { capacitor. } \\
\text { overheating, } \\
\text { destructive }\end{array}$ \\
\hline Undervoltage & $>1 \mathrm{~min} ; 0.85-1$ & $\begin{array}{l}\text { overheating in SMPS } \\
\text { without input boost } \\
\text { converter }\end{array}$ \\
\hline $\begin{array}{l}\text { Neutral to ground } \\
\text { voltage }\end{array}$ & $>10 \mathrm{~V}$ & $\begin{array}{l}\text { low probability of } \\
\text { occurrence of high } \\
\text { amplitude noise and } \\
\text { pulses } \\
\text { high probability or } \\
\text { high frequency of } \\
\text { occurence }\end{array}$ \\
\hline Noise & $500 \mathrm{~Hz}-5 \mathrm{MHz},>10 \mathrm{~V}$ & $\begin{array}{l}\text { unstability is } \\
\text { possible - destructive }\end{array}$ \\
\hline Harmonic distortion & THD<30\% & $\begin{array}{l}\text { no effect, if voltage } \\
\text { peak value remains } \\
\text { acceptable; if not, } \\
\text { the consequences are } \\
\text { similar to over or } \\
\text { undervoltage }\end{array}$ \\
\hline
\end{tabular}

- overvoltage above $110 \%$ - counting the total time and number of occurrences

- undervoltage lower than $85 \%$ during more than $30 \mathrm{~ms}$ counting the total time and number of occurrences

- positive notches with a peak value larger than $120 \%$ of the peak value of the nominal voltage, during a time $t$ : $1 \mathrm{~ms}<\mathrm{t}<10 \mathrm{~ms}$ - counting the number of occurrences

- interruptions, considering voltage lower than $40 \%$ of nominal value, during more than $30 \mathrm{~ms}$ - counting the total time and number of occurrences 


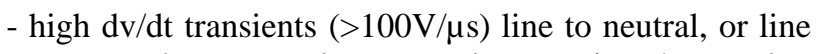
to ground, or neutral to ground - counting the number of occurrences

- Neutral to ground voltage $>10 \mathrm{~V}$ - counting the total time

- Neutral to ground high voltage spikes $>50 \mathrm{~V}$ - counting the number of occurrences

Power interruptions are defined at $40 \%$ of the nominal voltage, because this value is the minimum operating voltage for the extended range SMPS (230V nominal). For lower voltages we assume that all electronic equipments are shut down.

Over and under voltage measurements process includes a full bridge diode rectifier, a filtering capacitor, $1 \mathrm{~W}$ resistance, to avoid errors due to noise, and a high impedance differential amplifier (Fig. 7). Several voltage comparisons are then performed, with the output voltage of the amplifier and a precision voltage reference.

Neutral to ground voltage is measured through a resistance with a high impedance differential amplifier.

Fast transients are measured through a capacitive coupling with a non inductive resistor and high slew rate operational amplifiers.

The analog circuit is supplied by local batteries and is shielded. The outputs of this circuit are pulses with the duration of the occurrences. Those outputs are connected to a mother board with the following functions:

- a digital clock of 0.01 hour, based on a quartz high frequency clock

- sockets for six 2 digit BCD counters (occurrence counters) and four 4 digit BCD counters (time counters), in a bus with the input pulses and the BCD outputs

- a multiplexer that addresses each counter to a 4 digits led display, presenting times from 0 up to 99.99 hours and occurrences from 0 up to 100 ; the multiplexer is controlled manually

- a manual reset is inside the unit, to avoid operation errors.
The average power consumption is very low. Consequently, the internal batteries permit the autonomy of more than one month.

A 3-phase unit, using the same operating principles is now under development. A further version of this monitor integrates all digital circuits in a FPGA, in order to reduce the equipment size.

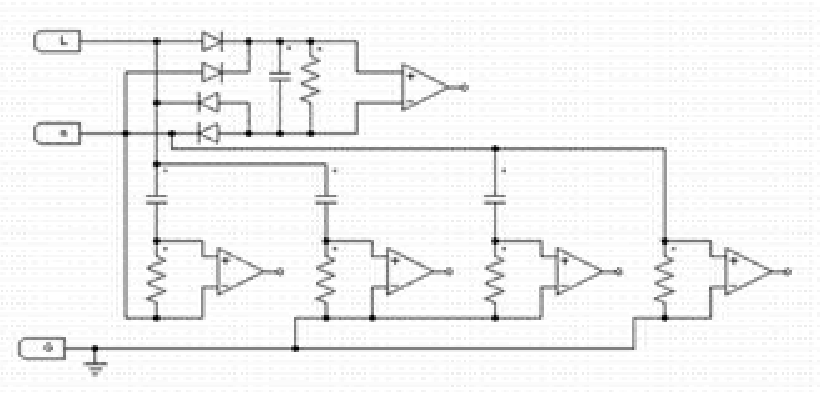

Fig. 7. PQ monitor: simplified diagram of the analog input

\section{Conclusion}

The authors developed a study of SMPS in order to understand the effects of power quality disturbances in the operation of electronic equipments. The conclusions of this study permit to select the relevant variables and measurements of power quality, concerning the reliability of electronic equipment. A low cost power quality analyser has been developed.

\section{References}

Henry Ott, Noise Reduction Techniques in Electronic Circuits, Wiley Interscience

Victor Anunciada, Sensitive User Requirements for Power Quality, EES-UETP Course on Power Quality, 1998

Roger C. Dugan, Mark F. McGranaghan, H. Beaty, Electrical Power Systems Quality, McGraw Hill 